SALES, Lilia Maia de Morais; CALOU, Marília Bitencourt C. A Cultura da Mediação e a Contraposição de Paradigmas: Uma Análise da Cooperação e Autonomia na Resolução de Conflitos. Revista Eletrônica Direito e Política, Programa de Pós-Graduação Stricto Sensu em Ciência Jurídica da UNIVALI, Itajaí, v.12, n.3, $3^{\circ}$ quadrimestre de 2017. Disponível em: www.univali.br/direitoepolitica - ISSN 1980-7791

\title{
A CULTURA DA MEDIAÇÃO E A CONTRAPOSIÇÃO DE PARADIGMAS: UMA ANÁLISE DA COOPERAÇÃO E AUTONOMIA NA RESOLUÇÃO DE CONFLITOS
}

\author{
THE MEDIATION CULTURE AND THE CONTRAPOSITION OF PARADIGMS: \\ AN ANALYSIS OF ETHICS AND OTHERNESS IN THE RESOLUTION OF CONFLICTS
}

Lilia Maia de Morais Sales ${ }^{1}$

Marília Bitencourt C. Calou²

SUMÁRIO: Introdução; 1 Mediação: uma nova cultura em prol da ética e da empatia; 2 A autonomia da mediação e o questionamento dos modelos preestabelecidos; 30 mediador: auxílio e protagonismo versus totalitarismo e neutralização; 4 Os paradigmas contrapostos; Considerações finais; Referências das fontes citadas

\section{RESUMO}

Neste trabalho, averígua-se o fenômeno das novas percepções da cultura da mediação com o objetivo de compreender se o novo paradigma proposto, pautado na cooperação e desenvolvimento de habilidades, rompe eficazmente com as teorias totalitárias, inaugurando uma nova forma de encarar-se o conflito e as relações humanas. Cumpre-se, desta forma, o objetivo geral de responder ao questionamento acerca da eficiência da mediação na inauguração de um novo paradigma que coaduna de melhor maneira com as novas formulações a respeito da realização do ser e do empoderamento social. Para tanto, utiliza-se de metodologia descritiva e exploratória, por meio de técnica de levantamento bibliográfico, atingindo conclusões no sentido da necessidade de se desenvolver uma contribuição mais efetiva no que compete aos novos modelos trazidos pela cultura da mediação, difundindo novas ideias as quais promovam o auxílio na busca por soluções em diversos âmbitos que apresentam problemas enfrentados na atualidade, como as crises no ensino jurídico, na formação das elites judiciais, no número de demandas recorrentes no poder judiciário dentre outros fatos que justificam o trabalho.

PALAVRAS-CHAVES: Cultura de Mediação; Teorias da Inimizade; Paradigma de Cooperação

\footnotetext{
${ }^{1}$ Bolsista de Produtividade em Pesquisa - CNPq, Pós-doutora pela Universidade de Columbia (Nova Iorque), doutora pela Universidade Federal de Pernambuco. Possui formação em mediação de conflitos na Universidade de Harvard, junto ao Program on Negotiation (EUA). É advogada, mediadora, professora titular da Universidade de Fortaleza (com dedicação aos Mestrados e Doutorado em Direito), Vice-Reitora de Pós-Graduação da Universidade de Fortaleza e coordena vários projetos de pesquisa com foco no estudo da mediação de conflitos. Av. Whashington Soares, 1321, Edson Queiroz, Fortaleza - CE, Brasil. E-mail: lilia@unifor.br

2 Doutoranda pela Universidade de Fortaleza. Orientanda da Professora Lília Maia de Morais Sales. Av. Whashington Soares, 1321, Edson Queiroz, Fortaleza - CE, Brasil. E-mail: mariliabitencourt@gmail.com
} 
SALES, Lilia Maia de Morais; CALOU, Marília Bitencourt C. A Cultura da Mediação e a Contraposição de Paradigmas: Uma Análise da Cooperação e Autonomia na Resolução de Conflitos. Revista Eletrônica Direito e Política, Programa de Pós-Graduação Stricto Sensu em Ciência Jurídica da UNIVALI, Itajaí, v.12, n.3, $3^{\circ}$ quadrimestre de 2017. Disponível em: www.univali.br/direitoepolitica

- ISSN 1980-7791

\section{ABSTRACT}

In this paper, the phenomenon of new perceptions of the culture of mediation are investigated in order to understand if the new proposed paradigm. It is based on cooperation and development of abilities, effectively breaks with totalitarian theories, inaugurating a new way of facing conflicts and human relations. Therefore is fulfilled the goal of responding to the question about the efficiency of mediation at the inauguration of a new paradigm, which harmonizes the best way with the new ideas regarding the realization of the being and social empowerment. For this purpose, it has used the descriptive and exploratory methodology by technique of bibliography research this study supports the need to develop a more effective contribution, as it is for the new models brought by the culture of mediation diffusing new ideas which promote aid in the search for solutions in different areas that present problems faced today, as crises in legal education, training of judicial elites, the number of recurring demands in power judiciary among others.

KEYWORDS: Cultural Mediation; Theories of Enmity; Cooperation Paradigm

\section{INTRODUÇÃO}

Do estudo das teorias do conflito, infere-se que em relação aos paradigmas de resolução de contendas (institucionais ou alternativos), demasiado se fez na orientação da prescrição de modelos que concebem a inimizade entre os homens e conjecturam a opressão e a submissão como alternativas de manutenção da paz social.

Constata-se por intermédio da filosofia de cooperação (sustentada por teóricos da mediação e negociação) que mencionadas teorias do conflito podem não subscrever a realização singular da personalidade humana, sendo, muitas vezes, ineficazes para a estruturação de uma sociedade harmônica em tão alto grau quanto se almeja.

Detecta-se que o primordial artifício de autodeterminação humana tão somente se instaura por meio da propensão cognitiva de rastrear coerência entre ações e intenções (ação corrente na mediação) e, depreende-se, no mesmo ensejo, que a liberdade (como faculdade primordial humana) configura-se partícula vital para a estruturação de sociedade que de nenhum modo deve contribuir para a neutralização da personalidade do indivíduo. Percebe-se desta forma, que os novos modelos alternativos parecem de melhor maneira realizar motivações básicas e essenciais para a individual realização humana. 
SALES, Lilia Maia de Morais; CALOU, Marília Bitencourt C. A Cultura da Mediação e a Contraposição de Paradigmas: Uma Análise da Cooperação e Autonomia na Resolução de Conflitos. Revista Eletrônica Direito e Política, Programa de Pós-Graduação Stricto Sensu em Ciência Jurídica da UNIVALI, Itajaí, v.12, n.3, $3^{\circ}$ quadrimestre de 2017. Disponível em: www.univali.br/direitoepolitica - ISSN 1980-7791

Constata-se também, que a realização do homem carece sempre do interminável avanço das capacidades de relacionamento. Pois que é possível afirmar que "viver não é mais que relacionar-se com o mundo"3, percebe-se que para que haja verdadeira individualização e desenvolvimento da personalidade, é essencial a extinção de todo totalitarismo, sem, no entanto, prescindir-se do desenvolvimento das capacidades necessárias para cooperação social (a necessidade do novo paradigma não é somente a autodeterminação e liberdade, mas a mediação orientada).

Afora todas as asserções já consolidadas, é possível constatar ainda, que mais do que estabelecer institutos que venham a apoiar-se na bondade ou perversidade nata do homem, deve-se crer na capacidade do desenvolvimento humano de habilidades, uma vez que o homem apático e entregue ao determinismo extremado em nada contribui para a sua própria realização ou para o progresso da sociedade.

Sabe-se que a instituição da distribuição da justiça em determinado tempo e lugar sofre a influência da cultura e da filosofia política produzida na época. As mudanças de percepção do conflito citadas acima, trazem novas visões cooperativas e inauguram também nos âmbitos institucionais, novos movimentos como a mediação de conflitos e seus recentes campos de estudo.

Por este motivo, neste trabalho, se pretende estudar o fenômeno da desejada mudança no paradigma de relações humanas no âmbito da resolução de conflitos encabeçadas por movimentos como os propostos pelas novas teorias da mediação. O problema deste trabalho é descrito pela seguinte indagação: a mediação inaugura efetivamente novo paradigma teórico no âmbito da resolução de conflitos? Há real quebra de antigas visões acerca do homem, da sociedade, do conflito e dos agentes protagonistas da transformação de demandas?

Pretende-se, de maneira breve e recortada, pesquisar os graus de concretização de orientações - tais como, a fortificação da consciência, a responsabilidade social e o empoderamento - que os diferentes paradigmas sustentados pelo processo

\footnotetext{
${ }^{3}$ GASSET, José Ortega y. A Rebelião das Massas. Rio de Janeiro: Ridendo, 2002. Tradução de: Herrera Filho. p. 67.
} 
SALES, Lilia Maia de Morais; CALOU, Marília Bitencourt C. A Cultura da Mediação e a Contraposição de Paradigmas: Uma Análise da Cooperação e Autonomia na Resolução de Conflitos. Revista Eletrônica Direito e Política, Programa de Pós-Graduação Stricto Sensu em Ciência Jurídica da UNIVALI, Itajaí, v.12, n.3, $3^{\circ}$ quadrimestre de 2017. Disponível em: www.univali.br/direitoepolitica - ISSN 1980-7791

judicial e pela mediação, carregam consigo, no intuito de responder questionamento acima exposto acerca da efetividade da mediação como marco fundamental de mudança paradigmática eficiente.

Em hipótese, acredita-se que o novo paradigma a que se pretende alcançar implicará profunda mudança cultural em prol da ética e da cooperação, rompendo eficazmente com as antigas teorias do conflito, impulsionando a necessidade do desenvolvimento de habilidades de cooperação, possibilitando o empoderamento de autodeterminação (necessário para a superação da inércia social) e contribuindo com a inauguração de uma nova visão do homem que seja sobremaneira mais compatível com a sociedade harmônica e de autodeterminação individual que se pretende construir.

Tem-se como objetivo geral: aferir de forma teórica a força da mediação como propulsora de mudança cultura que rompe com paradigma anteriormente descrito e que de melhor forma cumpre objetivos de liberdade, solidariedade e paz.

Como objetivos específicos tem-se: 1) Averiguar a descrição do paradigma a que se pretende superar, ressaltando a importância das questões da comunicação e dos modelos autocompositivos funcionais propostos pela escola de Harvard; 2) Ressaltar a influência da mediação como meio de promoção da autonomia individual e social do homem; 3) Analisar a postura do mediador em contraposição aos custos sociais decorrentes do padrão totalitário dos protagonistas de processo inquisitorial e; 4) Proceder com comparação dos paradigmas e posterior análise da questão da boa-fé com exposição da crença do ordenamento na cooperação e solidariedade.

Para tanto estrutura-se pesquisa descritiva e exploratória, de abordagem qualitativa, de natureza básica, por meio de técnica de revisão bibliográfica de autores modernos, principalmente ligados à escola de direito e negócios de Harvard, de onde tem partido as melhores acepções sobre o tema. Justifica-se referido artigo pela necessidade inadiável de modificar-se a atual forma de resolução de conflitos imposta à esta sociedade que, na maioria das vezes tem gerado violência, insatisfação e alienação da autodeterminação do homem. 
SALES, Lilia Maia de Morais; CALOU, Marília Bitencourt C. A Cultura da Mediação e a Contraposição de Paradigmas: Uma Análise da Cooperação e Autonomia na Resolução de Conflitos. Revista Eletrônica Direito e Política, Programa de Pós-Graduação Stricto Sensu em Ciência Jurídica da UNIVALI, Itajaí, v.12, n.3, $3^{\circ}$ quadrimestre de 2017. Disponível em: www.univali.br/direitoepolitica - ISSN 1980-7791

\section{MEdIAÇÃO: UMA NOVA CULTURA EM PROL DA ÉTICA E DA EMPATIA}

A observação da relação entre os homens faz supor importantes pontos de partida para que se possa estruturar teoria acerca do conflito e do consenso. No "mundo social" - que é como Habermas ${ }^{4}$ denomina o espaço concreto onde se é possível compartilhar conteúdos referentes ao mundo subjetivo e objetivo - a percepção da existência da comunicação é fator relevante.

Tal constatação tem real relevância uma vez que, é realidade inconteste que por meio desta via de compartilhamento de conteúdo, é possível se organizar relações e se atingir consensos ${ }^{5}$. Pode-se dizer que pelo menos as bases mais fundamentais da relação humana são constituídas pela concordância de pressupostos pragmáticos como a existência do mundo em que se atua.

Para Habermas ${ }^{6}$ e suas teses consensuais sobre a origem das sociedades, o homem vive em comunidade uma vez que percebe possível o entendimento subjetivo através da comunicação e mais refinadamente, da linguagem. Para o autor, toda comunicação, seja ela complexa ou por simples sinais e sons, ambiciona o alcance do consenso.

Desta forma, é possível dizer (não se adentrando às teorias sobre a verdade e a justiça) que, por meio da própria experiência humana, se pode afirmar a eficácia do agir comunicativo interpessoal, do entendimento mútuo e da gestão consensual de conflitos ${ }^{7}$.

Percebe-se, portanto, que diferentemente do que afirmaram os teóricos do conflito, a mediação e as soluções pacíficas são possíveis a todo homem que desenvolve em si as habilidades de construção de consensos. Tal entendimento alude a tempos longínquos: "(...) buscai resolver tua causa diretamente com teu próximo ${ }^{8 "}$ diz o provérbio guardado por judeus há milênios.

\footnotetext{
${ }^{4}$ HABERMAS, Jurgen. Consciência moral e agir comunicativo. p. 23.

5 HABERMAS, Jurgen. Consciência moral e agir comunicativo. Rio de Janeiro: Tempo Brasileiro, 2003. p. 39.

6 HABERMAS, Jurgen. Consciência moral e agir comunicativo. p. 104

7 SPENGLER. Fabiana Marion. A MEDIAÇÃo COMO PRÁTICA NO CONTEXTO COMUNITÁRIO. In: Aspectos atuais sobre a mediação e outros métodos extra e judiciais de resolução de conflitos. (Coord. Adolfo Braga Neto e Lilia Maia de Morais Sales). p. 34.

8 Provérbios 25:9.
} 
SALES, Lilia Maia de Morais; CALOU, Marília Bitencourt C. A Cultura da Mediação e a Contraposição de Paradigmas: Uma Análise da Cooperação e Autonomia na Resolução de Conflitos. Revista Eletrônica Direito e Política, Programa de Pós-Graduação Stricto Sensu em Ciência Jurídica da UNIVALI, Itajaí, v.12, n.3, $3^{\circ}$ quadrimestre de 2017. Disponível em: www.univali.br/direitoepolitica - ISSN 1980-7791

Confúcio, 700 anos antes de Cristo já defendia que o modo mais razoável para se atingir a harmonia entre as pessoas seria a mediação baseada na consideração recíproca dos indivíduos e em regras morais superiores ${ }^{9}$.

Também o cristianismo, à sua época, já profetizava os atuais entendimentos ao estabelecer o diálogo, a caridade e o amor como chaves para a resolução de conflitos. No evangelho de São Mateus $^{10}$, o Cristo, ensina com princípios da mediação, como em uma sociedade fraterna as contendas devem ser resolvidas:

Se teu irmão pecar contra ti, vai e, em particular com ele, conversem sobre a falta que cometeu. Se ele te der ouvidos, ganhaste a teu irmão. Porém, se ele não te der atenção, leva contigo mais uma ou duas pessoas, para que pelo depoimento de duas ou três testemunhas, qualquer acusação seja confirmada. Contudo, se ele se recusar a considerá-los, dizeio à igreja; então, se ele se negar também a ouvir a igreja, trata-o como pagão ou publicano. Com toda a certeza vos asseguro que tudo o que ligardes na terra terá sido ligado no céu, e tudo o que desligardes na terra terá sido desligado no céu.

Não só nos evangelhos, mas por toda a bíblia cristã encontram-se ensinamentos para o alcance da paz em comunidade. São Paulo de Tarso, em cartas escritas no ano 100 d.C., expõe fundamentos éticos admoestando as sociedades a viver o perdão ${ }^{11}$, a combater a postura de adversários ${ }^{12}$, a observar a boa-fé ${ }^{13}$ e a evitar a heterocomposição inquisitorial até quando possível:

Não há, porventura, nem ao menos um sábio entre vós, que possa julgar uma contenda entre irmãos? Contudo, ao invés disso, um irmão recorre ao tribunal contra outro irmão e apresenta tudo isso diante de incrédulos? ${ }^{14}$

\footnotetext{
9 SALES, Lilia Maia de Morais. A Escola na atualidade e a mediação escolar. Pensar: revista de ciências jurídicas. Fortaleza: Universidade de Fortaleza. Ano 2007, v. NESP. mês $A B R$, páginas 122-135 . p. 21.

10 Mateus 18:15.

11 "Zelai uns pelos outros e perdoai-vos mutuamente; caso alguém tenha algum protesto contra o outro, assim como o Senhor vos perdoou, assim também procedei" (Colossenses, 3:13).

12 "(...) contudo, não o consideres inimigo; pelo contrário, chamai a atenção dele como irmão" (Coríntios, 6:6-8).

13 "Quanto a este assunto, ninguém seduza ou tire proveito de seu irmão, porque o Senhor castigará todas essas práticas, como já vos advertimos com toda a certeza" (TESSALONICENSES, $4: 6)$.

14 Coríntios 6:5.
} 
SALES, Lilia Maia de Morais; CALOU, Marília Bitencourt C. A Cultura da Mediação e a Contraposição de Paradigmas: Uma Análise da Cooperação e Autonomia na Resolução de Conflitos. Revista Eletrônica Direito e Política, Programa de Pós-Graduação Stricto Sensu em Ciência Jurídica da UNIVALI, Itajaí, v.12, n.3, $3^{\circ}$ quadrimestre de 2017. Disponível em: www.univali.br/direitoepolitica - ISSN 1980-7791

Aludidos ensinamentos, remontam épocas distantes, mas continuam a servir a contemporaneidade de maneira eficaz. A mediação de conflitos e todo o estudo sobre a negociação e desenvolvimento de habilidades pessoais, atualmente parece inaugurar novo paradigma, resgatando a sabedoria milenar e construindo relações mais concernentes com as ideias de autodeterminação individual e social.

Crê-se a mediação como hipótese real de rompimento com os paradigmas históricos de conflito e adversariedade, que, de melhor forma firma novo paradigma sobremaneira mais concernente com as novas teorias da realização humana e cooperação entre seres, sociedade e nações.

A mediação, nos dizeres de Fabiana Marion Spengler ${ }^{15}$ "é uma maneira de instaurar a comunicação rompida entre as partes em função da posição antagônica instituída pelo litígio". O procedimento realiza tal feito, estabelecendo diálogo maximamente franco por meio do auxílio de técnicas de análise de fatos e investigação das circunstâncias materiais e abstratas que circundam as partes.

Visa-se por meio da mediação o alcance do consenso responsável, viabilizado pela restauração da comunicação, da expressão das necessidades, da exposição de conflitos reais e da reparação por meio do perdão e da confiança dos vínculos rompidos ${ }^{16}$.

Como visto anteriormente, os princípios da mediação de conflito não são uma novidade para o mundo. Cotidianamente a imensa maioria dos conflitos, encarados pelos indivíduos, são solucionados pela autocomposição. Mesmo a mediação como alternativa à via oficial de distribuição de justiça, também já é praticada há muito tempo. Vide os conflitos, por exemplo, já solucionados pela diplomacia entre países que evitaram centenas de guerras da histórica antiga à contemporânea.

Recentemente, porém, há quase meio século, a universidade de Harvard nos Estados Unidos, iniciou estudos sobre a mediação com o objetivo de torná-la uma

\footnotetext{
${ }^{15}$ SPENGLER. Fabiana Marion. A MEdIAÇÃo COMO PRÁTICA NO CONTEXTO COMUNITÁRIO. In: Aspectos atuais sobre a mediação e outros métodos extra e judiciais de resolução de conflitos. (Coord. Adolfo Braga Neto e Lilia Maia de Morais Sales). p. 39.

${ }^{16}$ SPENGLER. Fabiana Marion. A MEDIAÇÃo COMO PRÁTICA NO CONTEXTO COMUNITÁRIO. In: Aspectos atuais sobre a mediação e outros métodos extra e judiciais de resolução de conflitos. (Coord. Adolfo Braga Neto e Lilia Maia de Morais Sales). p. 40.
} 
SALES, Lilia Maia de Morais; CALOU, Marília Bitencourt C. A Cultura da Mediação e a Contraposição de Paradigmas: Uma Análise da Cooperação e Autonomia na Resolução de Conflitos. Revista Eletrônica Direito e Política, Programa de Pós-Graduação Stricto Sensu em Ciência Jurídica da UNIVALI, Itajaí, v.12, n.3, $3^{\circ}$ quadrimestre de 2017. Disponível em: www.univali.br/direitoepolitica - ISSN 1980-7791

teoria ${ }^{17}$. Discriminou-se inicialmente a universalidade de técnicas e mecanismos a fim de propiciar a divulgação de métodos eficazes empiricamente ou teoricamente desenvolvidos para negociações ${ }^{18}$.

Tal estudo sobre o desenvolvimento de habilidades e mediação demonstrou a possibilidade de formação de novo paradigma de resolução de conflitos, inaugurando-se nova fase no estudo da mediação, desta vez, mais firmemente fundamentada na filosofia-política, na sociologia, na psicologia e no direito.

O novo paradigma objetiva a transformação das relações de resolução de conflitos, a instituição da cooperação a despeito da adversariedade dos processos de negociação, a resignificação da visão do homem como projeto a ser alvo do desenvolvimento de habilidades (não mais importando para fins práticos a suposição de sua natureza exclusivamente boa ou má), a extinção dos processos de alienação da consciência e da vontade, a maximização da boa-fé e o fim da neutralização das partes em decisões inquisitoriais, com consequente inauguração de decisões compartidas, pautadas na busca criativa por inovação e valorização dos bens imateriais do relacionamento humano.

Em comparação com as filosofias do conflito, em rol não taxativo, vide tabela a seguir:

\footnotetext{
17 SALES, Lilia Maia de Morais. Aspectos atuais sobre a mediação e outros métodos extra e judiciais de resolução de conflitos. Rio de Janeiro: Gz, 2012. 330 p. 21.

18 SALES, Lilia Maia de Morais. Aspectos atuais sobre a mediação e outros métodos extra e judiciais de resolução de conflitos. p. 21-22.
} 
SALES, Lilia Maia de Morais; CALOU, Marília Bitencourt C. A Cultura da Mediação e a Contraposição de Paradigmas: Uma Análise da Cooperação e Autonomia na Resolução de Conflitos. Revista Eletrônica Direito e Política, Programa de Pós-Graduação Stricto Sensu em Ciência Jurídica da UNIVALI, Itajaí, v.12, n.3, $3^{\circ}$ quadrimestre de 2017. Disponível em: www.univali.br/direitoepolitica - ISSN 1980-7791

\begin{tabular}{|c|c|c|}
\hline & Filosofias da Inimizade & $\begin{array}{c}\text { Novo Paradigma da } \\
\text { Mediação }\end{array}$ \\
\hline $\begin{array}{c}\text { Relação entre as } \\
\text { partes } \\
\text { originárias do } \\
\text { conflito }\end{array}$ & $\begin{array}{l}\text { Adversariedade: as partes } \\
\text { do conflito são } \\
\text { consideradas adversárias e } \\
\text { buscam a imposição de } \\
\text { sucumbência à outra. O } \\
\text { modelo de relação é o de } \\
\text { "ganha-perde" em que uma } \\
\text { parte vence e a outra é } \\
\text { derrotada. }\end{array}$ & $\begin{array}{l}\text { Cooperação: as partes do } \\
\text { conflito objetivam am a } \\
\text { transformação da relação } \\
\text { por meio da construção } \\
\text { compartida e policêntrica do } \\
\text { consenso. O outro é } \\
\text { cooperador em uma relação } \\
\text { de busca por ganhos mútuos } \\
\text { e solução por múltiplas } \\
\text { portas. }\end{array}$ \\
\hline $\begin{array}{c}\text { Visão da } \\
\text { natureza humana }\end{array}$ & $\begin{array}{l}\text { O homem é mau por } \\
\text { natureza ou bom, mas } \\
\text { pervertido pela vida em } \\
\text { sociedade. Tem, portanto, } \\
\text { tendência nata à inimizade } \\
\text { e à guerra. Deve assim ser } \\
\text { contido por agente externo } \\
\text { superior. }\end{array}$ & $\begin{array}{l}\text { O homem é um projeto a ser } \\
\text { realizado por ele mesmo. } \\
\text { Portanto, o desenvolvimento } \\
\text { de habilidades de } \\
\text { cooperação é ponto } \\
\text { essencial para a construção } \\
\text { de uma vida social } \\
\text { harmônica. Há realismo e } \\
\text { esperança nesta visão. }\end{array}$ \\
\hline $\begin{array}{c}\text { Base de } \\
\text { construção de } \\
\text { uma sociedade } \\
\text { pacífica }\end{array}$ & $\begin{array}{l}\text { Totalitarismo e imposição } \\
\text { inquisitorial de decisões } \\
\text { externas aos conflitos } \\
\text { gerados no seio social. } \\
\text { Pacificação por meio da } \\
\text { obediência. }\end{array}$ & $\begin{array}{lr}\text { Autodeterminação } & \text { e } \\
\text { desenvolvimento } & \text { de } \\
\text { habilidades baseadas em } \\
\text { modelos de boa-fé e } \\
\text { cooperação. Pacificação por } \\
\text { meio do consenso. }\end{array}$ \\
\hline Conflito & $\begin{array}{l}\text { Obstáculo a ser superado } \\
\text { por meio da imposição de } \\
\text { força. Vício social nascido } \\
\text { da tendência humana à } \\
\text { guerra. }\end{array}$ & $\begin{array}{l}\text { Motor de inovações e } \\
\text { progresso, inevitável, porém } \\
\text { passível de manuseio e } \\
\text { transformação com possível } \\
\text { restauração de vínculos. }\end{array}$ \\
\hline $\begin{array}{c}\text { Forma eleita para } \\
\text { gerenciamento } \\
\text { de litígios }\end{array}$ & 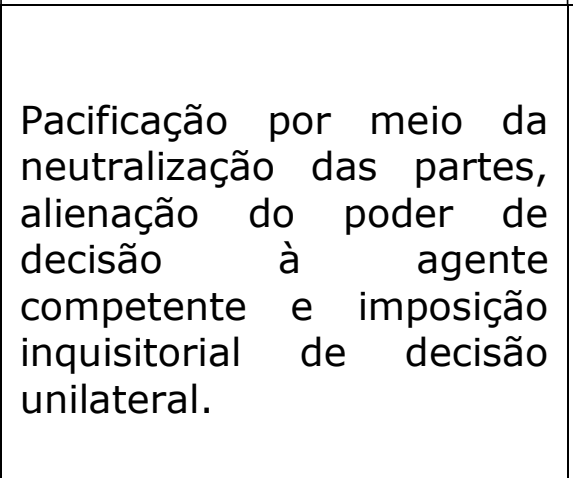 & $\begin{array}{l}\text { Construção compartida de } \\
\text { consenso, } \\
\text { protagonismo das partes } \\
\text { originárias do conflito. } \\
\text { Decisão baseada na busca } \\
\text { por inovação e cooperação. } \\
\text { Fomento } \\
\text { autodeterminação e da } \\
\text { habilidade de tomada de } \\
\text { decisões. }\end{array}$ \\
\hline
\end{tabular}


SALES, Lilia Maia de Morais; CALOU, Marília Bitencourt C. A Cultura da Mediação e a Contraposição de Paradigmas: Uma Análise da Cooperação e Autonomia na Resolução de Conflitos. Revista Eletrônica Direito e Política, Programa de Pós-Graduação Stricto Sensu em Ciência Jurídica da UNIVALI, Itajaí, v.12, n.3, $3^{\circ}$ quadrimestre de 2017. Disponível em: www.univali.br/direitoepolitica

- ISSN 1980-7791

O novo paradigma, como visto, resgata valores e práticas antigas e as mescla com a experiência acumulada e com os atuais estudos sobremaneira mais avançados. Sua história de divulgação é recente, tendo se iniciado, como já dito, nos Estados Unidos da América.

\section{A AUTONOMIA DA MEdiAÇÃO E O QUESTIONAMENTO DOS MODELOS PREESTABELECIDOS}

Foram os americanos que criaram o primeiro modelo de mediação institucional e iniciaram movimento de divulgação da ideia que findou por ser alvo de interesse em inúmeros países pelo mundo ${ }^{19}$. Alguns importantes movimentos auxiliaram essa divulgação.

Tais movimentos foram principalmente, o ressurgimento de tendências liberais no ocidente, o movimento de democratização gradativo das nações e o "fenômeno ramificado de constatação de que as fórmulas tradicionais formais de resolução de controvérsia não mais satisfaziam o cidadão"20.

Em relação às tendências liberais, diz-se que os movimentos que se apoiavam na ânsia de mitigação da importância do Estado nas relações particulares, acabaram por adotar para si a ideia de procedimento simplificado que poderia vir a retirar competências e poderes do judiciário.

Quanto ao processo de democratização, supõe-se que este contribuiu para a divulgação das ideias de mediação uma vez que exigia do cidadão maior protagonismo para que de máxima forma este viesse a assumir seu coeficiente de participação como sujeito de direitos e deveres nas democracias nascentes. Afirma-se que se é dado ao cidadão poder para definir parcialmente os rumos do Estado, é da mesma forma, aguardado que saiba, referido cidadão, administrar seus próprios conflitos ${ }^{21}$.

${ }^{19}$ Sales, Lilia Maia de Morais. Justiça e Mediação de conflito. Belo Horizonte: Del Rey, 2004. p.39.

20 Sales, Lilia Maia de Morais. Justiça e Mediação de conflito. p.39-40.

${ }^{21}$ SALES, Lilia Maia de Morais. Mediação de conflitos: família, escola e comunidade.

Florianópolis: Conceito Editorial, 2007. 317 p. 
SALES, Lilia Maia de Morais; CALOU, Marília Bitencourt C. A Cultura da Mediação e a Contraposição de Paradigmas: Uma Análise da Cooperação e Autonomia na Resolução de Conflitos. Revista Eletrônica Direito e Política, Programa de Pós-Graduação Stricto Sensu em Ciência Jurídica da UNIVALI, Itajaí, v.12, n.3, $3^{\circ}$ quadrimestre de 2017. Disponível em: www.univali.br/direitoepolitica - ISSN 1980-7791

Ainda em relação ao fenômeno de percepção da insatisfação com as soluções emanadas pelos meios oficiais, tal evento, deu-se principalmente pela tendência de personalização das contendas. A natureza e forma dos litígios pós-modernos, são tão complexas e distintas entre si que findaram por dificultar em muito a padronização e a busca por soluções baseadas em modelos estruturados pelos meios tradicionais. Sob tal entendimento Fabiana Marion Spengler ${ }^{22}$ afirma:

A sociedade contemporânea requer um novo modelo jurisdicional frente à ineficiência das tradicionais formas de tratamento de conflitos existentes. A função jurisdicional, atualmente ainda monopolizada pelo Estado, já não oferece respostas à conflituosidade produzida pela complexa sociedade hodierna, passando por uma crise de efetividade (quantitativa, mas principalmente qualitativa), que demanda a busca de alternativas. Da mesma forma, os métodos e os conteúdos utilizados pelo Direito para responder aos litígios não encontram adequação entre a complexidade das demandas, os sujeitos envolvidos e o instrumental jurídico a ser utilizado.

Neste contexto, percebe-se como nunca, o surgimento da necessidade por soluções ágeis, simplificadas, dinâmicas e rápidas para que haja real acompanhamento do ritmo das transações contemporâneas. O monopólio do engessamento aos modelos pré-estabelecidos, da dificultosa jornada travada para a realização de processos pelo estado e dos custos emocionais, de tempo e dinheiro, não se coaduna mais com os novos anseios de regulação e justiça.

Por estes motivos, diz-se que a mediação ganhou rápido apoio, sendo em muitos casos uma terceira via às posições políticas predefinidas e historicamente imisturáveis pela difícil ou inexistente comunicação. Também no campo do direito mostrou-se novidade revolucionária, sendo capaz de questionar modelos estabelecidos e engessados há muito tempo pela filosofia jurídica.

Mauro Capellettit ${ }^{23}$ identifica a mediação como "a terceira onda dos direitos sob o auspício do acesso material à justiça". No mesmo sentido Boaventura de Sousa

22 SPENGLER. Fabiana Marion. A mediação como prática no contexto comunitário. In: Aspectos atuais sobre a mediação e outros métodos extra e judiciais de resolução de conflitos. (Coord. Adolfo Braga Neto e Lilia Maia de Morais Sales). p. 56

${ }^{23}$ CAPELETTI, Mauro; GARTH, Bryan. El acceso a la justicia, la tendencia en el movimiento mundial para hacer efectivos los derechos. México: Fundo Econômico, 1996. p. 237. 
SALES, Lilia Maia de Morais; CALOU, Marília Bitencourt C. A Cultura da Mediação e a Contraposição de Paradigmas: Uma Análise da Cooperação e Autonomia na Resolução de Conflitos. Revista Eletrônica Direito e Política, Programa de Pós-Graduação Stricto Sensu em Ciência Jurídica da UNIVALI, Itajaí, v.12, n.3, $3^{\circ}$ quadrimestre de 2017. Disponível em: www.univali.br/direitoepolitica - ISSN 1980-7791

Santos $^{24}$ afirma que tal movimento pode vir a retirar o monopólio do direito regulador impositivo.

Porém, é importante entender que as mudanças trazidas pela mediação, apesar de ousadas e revolucionárias, não são de nenhuma maneira como anticorpos em um organismo. Não padecem as novas alternativas da necessidade de destruição dos antigos padrões. A mediação revoluciona, mas somando eficácia e viabilidade de metas aos modelos que já existem.

Desta forma, quando se diz que se pretende acabar com o monopólio da administração da justiça pelo Estado, ao contrário do que se poderia pensar, não se afirma a necessidade de mitigação da importância do Poder Judiciário. Como explica Fabiana Marion Spengler ${ }^{25}$, isto não ocorre, uma vez que, a insatisfação, engessamento e morosidade dos processos são em grande parte os verdadeiros responsáveis pelo descrédito em que caiu parte do serviço estatal de justiça.

Utilizar-se de meio mais adequado para resoluções de conflitos pontuais, pode vir a melhorar não somente em desobstrução de demanda os trabalhos do judiciário, mas também em especialização e possibilidade de dedicação à sua competência original (que, para os estudiosos a quem este trabalho se coaduna, defendem ser a de cumprir papel de instância de "ultima racio" na resolução de conflitos devendo-se dedicar-se, portanto, a questões complexas, que comportem desigualdades, graves violações a direitos humanos ou que possuam expressiva importância para a coletividade).

Para iniciar-se o entendimento dos procedimentos de mediação, é necessário que se entenda que tal processo, como dito, necessita de mudanças de paradigmas em muitos âmbitos da sociedade. Um deles, para além da resolução de conflitos, está na percepção ética exigida das pessoas expostas aos procedimentos de mediação.

24 SANTOS, Boaventura de Sousa. Os tribunais nas sociedades contemporâneas. PORTO: afrontamento. 1996. p. 123.

25 SPENGLER. Fabiana Marion. A mediação como prática no contexto comunitário. In: Aspectos atuais sobre a mediação e outros métodos extra e judiciais de resolução de conflitos. (Coord. Adolfo Braga Neto e Lilia Maia de Morais Sales). p. 39. 
SALES, Lilia Maia de Morais; CALOU, Marília Bitencourt C. A Cultura da Mediação e a Contraposição de Paradigmas: Uma Análise da Cooperação e Autonomia na Resolução de Conflitos. Revista Eletrônica Direito e Política, Programa de Pós-Graduação Stricto Sensu em Ciência Jurídica da UNIVALI, Itajaí, v.12, n.3, $3^{\circ}$ quadrimestre de 2017. Disponível em: www.univali.br/direitoepolitica - ISSN 1980-7791

Fabiana Spengler ${ }^{26}$ defende que a mediação, não é somente uma nova forma de tratamento jurisdicional dado à conflituosidade, mas uma "Nova cultura" que transcende os modelos de jurisdição e atinge a vida autônoma na busca pelo protagonismo do consenso, absolutamente necessário à responsabilização e empoderamento do cidadão. Nas palavras da autora:

O que se propõe é pensar a mediação não apenas como meio de acesso à justiça, aproximando o cidadão comum e 'desafogando' o Poder Judiciário. Pretende-se "discutir mediação" enquanto meio de tratamento de conflitos não quantitativamente, mas qualitativamente mais eficaz, proporcionando às partes a reaproximação do problema, organizando as "práticas" do seu tratamento, responsabilizando-se por tais escolhas e juriscontruindo os caminhos possíveis.

Para a autora, é essencial que cada homem, de maneira ética e responsável, consiga desenvolver habilidade de "lidar com a litigiosidade inerente à sua existência"27.Tal ambição de reforma de toda uma cultura necessita sem dúvida de trabalho árduo. Como defende Spengler ${ }^{28}$ o "local de trabalho" da mediação, não são os tribunais, tão somente, mas a sociedade em si, com toda sua gama de diversidades de valores e necessidades.

O grande desafio da mediação, portanto, vai além da criação de processo simplificado para o atingimento de consenso para o estabelecimento de decisão "pacificadora" que desobstruam o judiciário. Pretende-se enfrentar dissensos e a desordem dos conflitos, rever padrões, criar novos paradigmas e restabelecer a comunicação entre os homens.

Tal movimento inicia-se de maneira capilarizada, porém, parece por movimento natural, ter-se atrelado justamente ao campo do direito. Nesse processo a figura do mediador é ressaltada. Diferentemente da já conhecida tríade de autoridade

26 SPENGLER. Fabiana Marion. A mediação como prática no contexto comunitário. In: Aspectos atuais sobre a mediação e outros métodos extra e judiciais de resolução de conflitos. (Coord. Adolfo Braga Neto e Lilia Maia de Morais Sales). p. 39.

27 SPENGLER. Fabiana Marion. A mediação como prática no contexto comunitário. In: Aspectos atuais sobre a mediação e outros métodos extra e judiciais de resolução de conflitos. (Coord. Adolfo Braga Neto e Lilia Maia de Morais Sales). p. 44.

28 SPENGLER. Fabiana Marion. A mediação como prática no contexto comunitário. In: Aspectos atuais sobre a mediação e outros métodos extra e judiciais de resolução de conflitos. (Coord. Adolfo Braga Neto e Lilia Maia de Morais Sales). p. 48. 
SALES, Lilia Maia de Morais; CALOU, Marília Bitencourt C. A Cultura da Mediação e a Contraposição de Paradigmas: Uma Análise da Cooperação e Autonomia na Resolução de Conflitos. Revista Eletrônica Direito e Política, Programa de Pós-Graduação Stricto Sensu em Ciência Jurídica da UNIVALI, Itajaí, v.12, n.3, $3^{\circ}$ quadrimestre de 2017. Disponível em: www.univali.br/direitoepolitica - ISSN 1980-7791

estabelecida no processo, surge repaginada relação presidida por nascente personagem que parece carregar sobre si grande responsabilidade na formatação do novo paradigma.

\section{O MEDIADOR: AUXÍlIO E PROTAGONISMO VERSUS TOTALITARISMO E NEUTRALIZAÇÃo}

No novo paradigma trazido pela mediação, o juiz é substituído, pelo menos em um primeiro momento, pela figura do mediador. Do mediador, como aguardado, requer-se postura ética irrepreensível devido à natureza de sua função de auxílio e ensino dos processos. Entende-se a necessidade da presença de profissional que coordene o processo coparticipativo e autônomo de tomada de decisão, uma vez que se carece de passagem por período de transição até que se institua (ou se recupere) o costume da solução dirigida exclusivamente pelas partes.

Depois de séculos (ou mesmo milênios) de submissão a decisões totalitárias é normal a arraigada sedimentação de cultura nesse sentido. As consequências psicológicas da inquisição, imposição e violência instituída não serão facilmente expurgadas do inconsciente individual. Necessário se faz este eficaz primeiro modelo de mediação para remodelamento de novos paradigmas para as gerações vindouras que continuarão a contribuir para o processo de total empoderamento individual a despeito dos modelos inquisitoriais de submissão.

Há corrente, no entanto, que defende a imprescindibilidade perpétua do mediador, que, mesmo em uma cultura de autonomia nas resoluções de conflito, seria necessário para auxiliar o processo de racionalização de contendas, uma vez que estas se iniciam muitas vezes anuviadas pela mágoa, desconfiança, preocupação etc 29 .

Tais barreiras, descritas por Hannah Arendt ${ }^{30}$ como fruto da interseção entre a teia de relacionamentos imateriais e a de negócios concretos (ou como explicado por

\footnotetext{
${ }^{29}$ ARENTD, Hannah. A condição Humana. Tradução de Roberto Raposo. $11^{a}$. ed. Rio de Janeiro: Forense Universitária, 2010, p. 188

30 ARENTD, Hannah. Eichann em Jerusalém: um relato sobre a banalidade do mal. Tradução de José Rubens Siqueira. 11a.ed. São Paulo: Companhia das letras, 2004, p. 104.
} 
SALES, Lilia Maia de Morais; CALOU, Marília Bitencourt C. A Cultura da Mediação e a Contraposição de Paradigmas: Uma Análise da Cooperação e Autonomia na Resolução de Conflitos. Revista Eletrônica Direito e Política, Programa de Pós-Graduação Stricto Sensu em Ciência Jurídica da UNIVALI, Itajaí, v.12, n.3, $3^{\circ}$ quadrimestre de 2017. Disponível em: www.univali.br/direitoepolitica - ISSN 1980-7791

Jürgen Habermas ${ }^{31}$ geradas pelos três níveis sociais em que o homem atua mundo objetivo, o mundo social e o mundo subjetivo ${ }^{32}$ ) se não positivamente transpostas com a ajuda do mediador e seu universo de conhecimentos e experiências sobre técnicas e conflitos, podem vir a impedir, até mesmo as resoluções inquisitoriais e adversariais, que dirá processos pacíficos baseados em consensos não executórios.

Por este motivo, há aqueles que defendam a presença insubstituível do mediador, mesmo após o atingimento gradativo pela sociedade dos novos paradigmas. Este trabalho não se deterá neste tema uma vez que muitos são os fatores que deverão influir na evolução do paradigma de cooperação que se pretende instituir, e, por isso, abre-se mão da previsão por falta de substrato para fazê-la.

O que se deve saber, atualmente, é que a presença do mediador hoje é de necessidade inafastável e deve pautar-se na máxima defesa da ética, uma vez que, é da natureza do próprio procedimento de mediação, a boa-fé, a cooperação e a transformação e análise real do conflito em pauta.

Diante deste entendimento abre-se uma nova meta para a instauração de método sobremaneira mais adequado de resolução de conflito: a formação de profissionais capacitados a viabilizar a prática corriqueira da mediação. Tal formação é demasiadamente dificultosa uma vez que se pretende formar pioneiros num paradigma que se ergue contra a cultura em que se está imerso.

Tal formação encontra também grandes desafios, uma vez que mais do que em repasse de conteúdo de absorção cognitiva, pauta-se em processo de desenvolvimento de hábitos, habilidades, virtudes e valores que se propugna fazer aderir à personalidade do indivíduo ${ }^{33}$.

\footnotetext{
31 HABERMAS, Jurgen. Consciência moral e agir comunicativo. p. 104.

$32 \mathrm{O}$ autor explica que o mundo da vida em que agem os atores sociais é formado por três âmbitos de atuação, o mundo objetivo (que pode ser concretamente manuseado, e sob o qual se pode descrever de maneira real os fenômenos conhecidos), o mundo social (espaço de realização das relações interpessoais de comunicação e uso da linguagem) e o mundo subjetivo (acessado individualmente pelo sujeito que o possui e somente expressado por voluntaria ação, consiste no conjunto de experiências e sentimentos reunidos pelo homem e singularmente organizados).
}

33 WARAT, Luis Alberto. Introdução geral ao direito. Epistemologia jurídica na modernidade. Porto Alegre: Safe, 1995. p. 67. 
SALES, Lilia Maia de Morais; CALOU, Marília Bitencourt C. A Cultura da Mediação e a Contraposição de Paradigmas: Uma Análise da Cooperação e Autonomia na Resolução de Conflitos. Revista Eletrônica Direito e Política, Programa de Pós-Graduação Stricto Sensu em Ciência Jurídica da UNIVALI, Itajaí, v.12, n.3, $3^{\circ}$ quadrimestre de 2017. Disponível em: www.univali.br/direitoepolitica - ISSN 1980-7791

Neste ponto, é possível perceber que os estudiosos e entusiastas da mediação não advogam em prol do determinismo cético das filosofias do conflito, mas por uma visão de esperança (significativamente mais relevante) de que é dado a todo homem a capacidade de desenvolver em si virtudes e habilidades que possibilitem a construção de tecido social harmônico, tanto quanto mais apto ao seu desenvolvimento pessoal ${ }^{34}$.

As virtudes elencadas por Sales ${ }^{35}$ servem de exemplo para que se compreenda o desafio da formação de mediadores. Dentre elas, a ética, a humildade, a capacidade de cooperação, o perdão, a solidariedade e a autodeterminação mostram-se relevantes.

Outro desafio na formação dos mediadores é o necessário (porém ainda não definido) entendimento global do sentido da mediação. Este entendimento impede que a mediação se torne simples repetição menos formal e simplificada do procedimento oficial padrão. Neste momento de transição, todos os detalhes são importantes para a quebra do paradigma.

É imprescindível a total definição da diferença entre os papéis e funções do juiz e do mediador. A despeito da personificação do imenso poder do estado na pessoa do juiz, é necessário que o mediador se revista da consciência de seu papel auxiliar na resolução do conflito. Antes de qualquer oficialização de sentenças, deve-se manter a serviço das partes, fazendo-as refletir sobre o passado, presente e futuro ${ }^{36}$.

Muitas são as contribuições da mediação na formação de novo paradigma de resolução de conflitos. As diferenças entre os dois procedimentos, oficial e adequado, são expressivas e, hipoteticamente, se pode afirmar que o novo procedimento da mediação em muito mais se configura com as ideias de Hannah Arendt de formação de ambiente pacífico para a realização da personalidade

\footnotetext{
${ }^{34}$ WARAT, Luis Alberto. Introdução geral ao direito. Epistemologia jurídica na modernidade. p. 69.

35 SALES, Lilia Maia de Morais. Aspectos atuais sobre a mediação e outros métodos extra e judiciais de resolução de conflitos. p. 24.

36 SALES, Lilia Maia de Morais. Aspectos atuais sobre a mediação e outros métodos extra e judiciais de resolução de conflitos. p. 24.
} 
SALES, Lilia Maia de Morais; CALOU, Marília Bitencourt C. A Cultura da Mediação e a Contraposição de Paradigmas: Uma Análise da Cooperação e Autonomia na Resolução de Conflitos. Revista Eletrônica Direito e Política, Programa de Pós-Graduação Stricto Sensu em Ciência Jurídica da UNIVALI, Itajaí, v.12, n.3, $3^{\circ}$ quadrimestre de 2017. Disponível em: www.univali.br/direitoepolitica - ISSN 1980-7791

individual e parece verdadeiramente romper com as velhas ideias das filosofias da inimizade e das decisões totalitárias. No subtópico seguinte se fará análise das grandes novidades trazidas pela mediação de conflito.

\section{OS PARADIGMAS CONTRAPOSTOS}

Como dito anteriormente, o entendimento global do real significado da mediação em muito pode contribuir para que as iniciativas de seus pioneiros divulgadores maximamente se coadunem com os anseios iniciais dos teóricos da mediação. Dentre os papéis da mediação, encontra-se a ideia de superação do antigo paradigma da adversariedade e, neste intento, suas metas se apresentam.

Dentre elas pode-se citar: a cooperação como ponto de partida na busca por soluções; o aprendizado dos processos de gerenciamento e racionalização de emoções; o estímulo à inovação e criatividade para a resolução de conflitos aparentemente engessados em litígios; a restauração do tecido social; a restauração de vínculos de trato sucessivo; o desenvolvimento de habilidades de confiança e perdão que venham a influir na propagação da boa-fé nas relações humanas e a busca pela global e real análise dos conflitos por meio do escrutínio de interesses, necessidades e conflitos reais entre as partes.

Em relação à cooperação, sabe-se que as filosofias do conflito que encaram o homem como inimigo do homem, ou como ser incapaz de estabelecer relações não pautadas em interesses escusos e nada fraternos, advogam em favor de uma constituição social pautada no controle ou na crença em uma autorregulação abstrata e ilusória das regras naturais ou econômicas.

Diferentemente de tais teorias a mediação observa o homem como um projeto em desenvolvimento e, ao mediador, cabe realizar o auxílio às partes para que estas possam romper com visões limitadas e individualistas e partir para posturas menos competitivas e adversariais e mais cooperativas e fraternas.

Perceber o valor da crença na capacidade humana de desenvolver virtudes e habilidade de relacionamento pode parecer algo distante dos mais bem cotados cientificamente, projetos objetivos e de fácil controle por cálculos matemáticos ou formulas legais, mas não se deve prescindir da importância da análise e percepção 
SALES, Lilia Maia de Morais; CALOU, Marília Bitencourt C. A Cultura da Mediação e a Contraposição de Paradigmas: Uma Análise da Cooperação e Autonomia na Resolução de Conflitos. Revista Eletrônica Direito e Política, Programa de Pós-Graduação Stricto Sensu em Ciência Jurídica da UNIVALI, Itajaí, v.12, n.3, $3^{\circ}$ quadrimestre de 2017. Disponível em: www.univali.br/direitoepolitica - ISSN 1980-7791

da alma humana de maneira, desta vez, verdadeiramente, mais realista, para que se possa atingir a sociedade da cooperação e da caridade idealizada por grandes homens de ânimo incansável.

Para a mediação, o gerenciamento de emoções é ferramenta essencial para a divulgação dos novos paradigmas. Desde cedo o homem é chamado a romper com a bestialidade inicial, a aprender o universo ao seu redor e a constituir-se homem inteiro. O veneno das filosofias contaminadas incluídas em meio à formação do atual cenário ocidental de trabalho e progresso passou a contabilizar o sucesso de um homem em ganhos monetários e lucros.

Ocorre que é o homem capaz de deter não apenas bens materiais, mas os imateriais também e este dado Ihe foi retirado da formação básica. A formação de seres humanos capazes de cultivar estabilidade emocional a ponto de em meio ao conflito conseguir romper os obstáculos da raiva e da mágoa para compreender e cooperar, é trabalho árduo, mas não impossível.

O mediador acumula estas funções, quando em trabalho pontual (de ensino ou mediação de conflitos) leva as partes a compreender a necessidade do gerenciamento de emoções, ajudando-as por meio de técnicas largamente experimentadas no desenvolvimento da temperança, contra os rompantes de cólera, ira, frustração etc. que impedem a visão racional e eficiente do problema que se pretende solucionar ${ }^{37}$.

Dentre as funções do mediador também está a capacidade de auxiliar na extensão do campo criativo de possíveis soluções, não se mantendo, as partes, restritas ao modelo de solução das leis. Diante, ainda, de conflitos materialmente verdadeiramente irresolúveis, o mediador contribui para a percepção que, apesar das teorias de bens escassos, deve-se sempre somar ao quantum debatido a universalidade de bens imateriais com o fim de trazer ganhos no âmbito da restauração de vínculos e reestabelecimento do tecido social.

\footnotetext{
37 SALES, Lilia Maia de Morais. Aspectos atuais sobre a mediação e outros métodos extra e judiciais de resolução de conflitos. p. 25.
} 
SALES, Lilia Maia de Morais; CALOU, Marília Bitencourt C. A Cultura da Mediação e a Contraposição de Paradigmas: Uma Análise da Cooperação e Autonomia na Resolução de Conflitos. Revista Eletrônica Direito e Política, Programa de Pós-Graduação Stricto Sensu em Ciência Jurídica da UNIVALI, Itajaí, v.12, n.3, $3^{\circ}$ quadrimestre de 2017. Disponível em: www.univali.br/direitoepolitica - ISSN 1980-7791

A mediação também traz para si como meta a inovação, em plano macro, para contribuir com a ansiada pacificação social, desta vez, por meio do correto manejo do conflito fundamentado em novo, realista e esperançoso olhar do homem.

Somam-se a esses objetivos o alcance do auxílio ao desenvolvimento do perdão e da confiança, explicados por Hannah Arendt ${ }^{38}$ como motores essenciais da dinâmica do relacionamento humano. Somente com tais habilidades é possível, para a autora, e para os filósofos da mediação, a possibilidade de vencer conflitos ditos irresolúveis devido à exposição da autoculpa compartilhada e cura da mágoa recíproca ${ }^{39}$.

Afora isso, ambiciona-se a transformação do diálogo e da comunicação humana. Pretende-se fazer e ensinar a possibilidade do eficiente escrutínio dos conflitos trabalhados por meio da exposição das reais insatisfações. Explicam-se, devido às dificuldades de comunicação existentes entre os homens, muitas vezes se está a verbalizar em uma negociação a simulação de interesses (propositalmente ou devido ao errado discernimento e autoconhecimento das próprias necessidades e emoções). Ao mediador é dado auxiliar e ensinar métodos corretos de investigação de conflitos para possibilitar melhor e mais eficaz comunicação entre os homens. Por fim, porém, em nenhum instante menos importante, a mediação quer com suas novas teorias, principalmente, extinguir a neutralização das partes (de simples expectadores) no processo de resolução de conflito para isto atingir a sociedade de líderes protagonistas empoderados dos meios adequados para fazer valer sua autonomia e realização (como deve ser a comunidade de homens livres e fraternos que vencem os totalitarismos e alcançam o real desenvolvimento humano).

Conclui-se por este trabalho que a mediação contribui eficazmente e de máxima forma para a realização de sociedade - tanto quanto possível - pacífica, justa e solidária. Entende-se também que tais novas teorias rompem de maneira efetiva com os antigos paradigmas de não cooperação e adversariedade, inaugurando novo modelo pautado na cooperação e realização da personalidade humana.

\footnotetext{
38 ARENTD, Hannah. A condição Humana. p. 180.

39 SALES, Lilia Maia de Morais. Aspectos atuais sobre a mediação e outros métodos extra e judiciais de resolução de conflitos. p. 28.
} 
SALES, Lilia Maia de Morais; CALOU, Marília Bitencourt C. A Cultura da Mediação e a Contraposição de Paradigmas: Uma Análise da Cooperação e Autonomia na Resolução de Conflitos. Revista Eletrônica Direito e Política, Programa de Pós-Graduação Stricto Sensu em Ciência Jurídica da UNIVALI, Itajaí, v.12, n.3, $3^{\circ}$ quadrimestre de 2017. Disponível em: www.univali.br/direitoepolitica - ISSN 1980-7791

Percebe-se no decorrer da pesquisa que apesar das teorias que desacreditam a convivência pacífica e fraterna entre os homens sem a imposição de uma moral artificial forte, a mediação e as filosofias que a precedem e fundamentam, tem demonstrado a efetividade do desenvolvimento de habilidades de autodeterminação e cooperação livres.

Por meio dos estudos da Boa-Fé Objetiva, entende-se também que o ordenamento reconhece a ética e a capacidade de empoderamento dos indivíduos. A mediação, neste contexto, apresenta-se como ferramenta eficaz e possível para realização não só dos anseios abstratos humanos, mas dos Objetivos Fundamentais da República.

Entende-se tal afirmação ao analisar-se a reaproximação entre direito e ética e a positivação do princípio da boa-fé objetiva que demonstram que o ordenamento expressa a crença social de que cada indivíduo pode em sua subjetividade perceber o modelo ético, justo e honesto de conduta que se espera dele em seu trato cotidiano. Não é a moral artificial, a avidez pelo ganho ou Leviatã maligno que o ensina a agir, mas a sua própria percepção dos elementos essenciais ao convívio. O direito, como ciência do dever ser, ao proclamar a Boa-fé objetiva como dever de conduta a ser observado reconheceu a capacidade de o indivíduo perceber a ética e a justiça, contradizendo assim as essenciais teorias do conflito.

A estrutura da mediação, por esta ótica, passa então a ser instituto que se encaixa com perfeição como ferramenta na busca pelo alcance dos Objetivos Fundamentais da República de construção de uma sociedade justa, livre e solidária.

Desta forma, busca-se na mediação instituto que de melhor forma, no âmbito das questões da resolução de conflito, contribui de maneira eficaz para o alcance dos objetivos constitucionais. A mediação, por meio da promoção do gerenciamento de emoções e fomento à cooperação e justiça, demonstra ser instituto capaz de contribuir largamente com tais Objetivos e ajudar na formação de uma sociedade maximamente livre, justa, solidária, inovadora e desenvolvida.

Percebe-se, por este trabalho, a necessidade de aprofundar-se os estudos acerca da mediação, uma vez que esta, tendo nascido timidamente, pode conter em si potência para a resolução de grandes problemas enfrentados hoje. 
SALES, Lilia Maia de Morais; CALOU, Marília Bitencourt C. A Cultura da Mediação e a Contraposição de Paradigmas: Uma Análise da Cooperação e Autonomia na Resolução de Conflitos. Revista Eletrônica Direito e Política, Programa de Pós-Graduação Stricto Sensu em Ciência Jurídica da UNIVALI, Itajaí, v.12, n.3, $3^{\circ}$ quadrimestre de 2017. Disponível em: www.univali.br/direitoepolitica - ISSN 1980-7791

\section{CONSIDERAÇÕES FINAIS}

O presente trabalho propôs a averiguação do fenômeno da mediação como elemento de quebra de paradigma cultural no âmbito da resolução de conflitos. Teve-se como hipótese que em relação a modelo anteriormente observado, a mediação representa arrojada mudança que de melhor maneira se coaduna com os ideais de justiça, paz e solidariedade sustentados pelo ordenamento.

De maneira cada vez mais expressiva o processo judicial foi ganhando ao longo da história, papel protagonista na resolução de litígios inerentes às relações humanas. Com o crescimento de sua representatividade, problemas, decorrentes dos mais variados fatores surgiram, dentre eles, a neutralização das partes, o totalitarismo de sentença e a inquisitorialidade e adversariedade próprias do processo que acabaram por gerar problemas sociais tais como falta de autonomia e habilidade de solucionar conflitos do homem comum.

Neste trabalho, no primeiro tópico, foi abordada a questão da empatia e ética próprias da mediação. Fez-se descrição da importância da comunicação e da visão cooperativa para a restauração constante do ambiente social. Estudou-se a mediação como habilidade indispensável em processo de aprendizado desta restauração. Estudou-se ainda a força e eficácia dos modelos autocompositivos e as novas percepções dos modelos apresentados pelos norte americanos em matéria de negociação e mediação. Fez-se também comparação entre o antigo e o novo paradigma, concluindo-se que a mediação procede com visão inovadora da natureza, sociedade e conflito humano.

No segundo tópico estudou-se a mediação como elemento social de aprendizado que, por meio da resolução orientada de conflitos diários, em teoria, pode devolver ao cidadão a autonomia necessária para a validade das relações sociais. O terceiro tópico, por sua vez, abordou a postura do mediador frente o autoritarismo próprio da decisão judicial que, conforme aferido, pode, aos poucos, influenciar a modificação das relações em formato macro, concedendo transformações necessárias no sentido da autonomia e da satisfação cooperativa.

No quarto tópico, procedeu-se com comparação dos paradigmas e conclusão de que a cooperação presente na mediação por: a) inaugurar novo paradigma (como 
SALES, Lilia Maia de Morais; CALOU, Marília Bitencourt C. A Cultura da Mediação e a Contraposição de Paradigmas: Uma Análise da Cooperação e Autonomia na Resolução de Conflitos. Revista Eletrônica Direito e Política, Programa de Pós-Graduação Stricto Sensu em Ciência Jurídica da UNIVALI, Itajaí, v.12, n.3, $3^{\circ}$ quadrimestre de 2017. Disponível em: www.univali.br/direitoepolitica - ISSN 1980-7791

visto no primeiro tópico); b) gerar autonomia e comunicação eficaz (como visto no segundo tópico); c) e criar novo modelo de relacionamento na resolução de conflitos - mediação e não inquisição (como visto no terceiro tópico), inaugura eficazmente novo paradigma que de maneira eficaz contribui para os objetivos fundamentais da república.

Ainda no quarto tópico foi assinalado que a cooperação não é utopia descrita por filósofos idealistas, mas crença exposta, inclusive, no ordenamento jurídico. Pela exigência da boa-fé, percebe-se que há certeza acerca da possibilidade de desenvolvimento da capacidade de cooperação e ética no ser humano. Conclui-se, neste contexto, que a mediação é mecanismo que, rompendo paradigmas anteriormente adotados, de melhor forma constitui-se como prática social propulsora da solidariedade, da paz, da justiça e da cooperação.

\section{REFERÊNCIAS DAS FONTES CITADAS}

ARENTD, Hannah. A condição Humana. Tradução de Roberto Raposo. 11a. ed. Rio de Janeiro: Forense Universitária, 2010, 470p.

. Eichmann em Jerusalém: um relato sobre a banalidade do mal. Tradução de José Rubens Siqueira. 11a.ed. São Paulo: Companhia das letras, 2004, 336p.

. Homens em tempos sombrios. São Paulo: companhia das letras, 1987, 249p.

Origens do totalitarismo. São Paulo: Companhia das Letras, 2000, 562p.

CAPELETTI, Mauro; GARTH, Bryan. El acceso a la justicia, la tendencia en el movimiento mundial para hacer efectivos los derechos. México: Fundo Econômico, 1996.

GASSET, Ortega y. A rebelião das massas. São Paulo: Ridendo Castigat Mores, 2000. Disponível em: <http://www.ebooksbrasil.org/adobeebook/ortega.pdf>. Acesso em: 17 maio 2016.

GASSET, José Ortega y. A Rebelião das Massas. Rio de Janeiro: Ridendo, 2002. Tradução de: Herrera Filho. 
SALES, Lilia Maia de Morais; CALOU, Marília Bitencourt C. A Cultura da Mediação e a Contraposição de Paradigmas: Uma Análise da Cooperação e Autonomia na Resolução de Conflitos. Revista Eletrônica Direito e Política, Programa de Pós-Graduação Stricto Sensu em Ciência Jurídica da UNIVALI, Itajaí, v.12, n.3, $3^{\circ}$ quadrimestre de 2017. Disponível em: www.univali.br/direitoepolitica

- ISSN 1980-7791

HABERMAS, Jurgen. Consciência moral e agir comunicativo. Rio de Janeiro: Tempo Brasileiro, 2003.

SALES, Lilia Maia de Moraes. A Escola na atualidade e a mediação escolar. Pensar: revista de ciências jurídicas. Fortaleza: Universidade de Fortaleza. Ano 2007, v. NESP. mês ABR, páginas 122-135.

A Mediação comunitária: instrumento de democratização da justiça. Fortaleza: Universidade de Fortaleza. Pensar: revista de ciências jurídicas. Ano 2002, v., n. 7, mês FEV, páginas 171-180.

Aspectos atuais sobre a mediação e outros métodos extra e judiciais de resolução de conflitos. Rio de Janeiro: Gz, 2012. 330 p.

Estudos sobre a efetivação do direito na atualidade: a cidadania em debate. Fortaleza: Universidade de Fortaleza, 2006.

Estudos sobre mediação e arbitragem. Rio de Janeiro: Abc, 2003. $229 \mathrm{p}$

Justiça e Mediação de conflito. Belo Horizonte: Del Rey, 2004. 334 p.

Mediação de conflitos: família, escola e comunidade. Florianópolis: Conceito Editorial, 2007. 317 p.

; ANDRADE, Denise Almeida. Mediação em perspectiva: orientações para mediadores comunitários. Fortaleza: Universidade de Fortaleza, 2004. 146 p.

; VASCONCELOS, Monica Carvalho. Mediação familiar: um estudo histórico-social das relações de conflitos nas famílias contemporâneas. Rio de Janeiro: Expressão Gráfica, 2006. 183 p.

SANTOS, Boaventura de Sousa. Os tribunais nas sociedades comtemporâneas. PORTO: afrontamento. 1996.

SPENGleR. Fabiana Marion. A MEdiAÇÃo COMO PRÁtICA NO CONTEXTO COMUNITÁRIO. In: Aspectos atuais sobre a mediação e outros métodos extra e 
SALES, Lilia Maia de Morais; CALOU, Marília Bitencourt C. A Cultura da Mediação e a Contraposição de Paradigmas: Uma Análise da Cooperação e Autonomia na Resolução de Conflitos. Revista Eletrônica Direito e Política, Programa de Pós-Graduação Stricto Sensu em Ciência Jurídica da UNIVALI, Itajaí, v.12, n.3, $3^{\circ}$ quadrimestre de 2017. Disponível em: www.univali.br/direitoepolitica - ISSN 1980-7791

judiciais de resolução de conflitos. (Coord. Adolfo Braga Neto e Lilia Maia de Morais Sales). Rio de Janeiro: Gz, 2012.

WARAT, Luis Alberto. Introdução geral ao direito. Epistemologia jurídica na modernidade. Porto Alegre: Safe, 1995.

Submetido em: novembro de 2017

Aprovado em: dezembro de 2017 